Onkologie 1991;14:93

\title{
Impressum, Vol. 14, No. 2, 1991
}

\section{Herausgeber}

\section{S. KARGER}

Verlag für Medizin und Naturwissenschaften GmbH, Postfach 1724, D-8034 Germering (BRD)

Presserechtlich verantwortlich: Walter Kunz, Gesellschafter

Offizielles Organ

der Deutschen Gesellschaft für Hämatologie und Onkologie, der Österreichischen Gesellschaft für Hämatologie und Onkologie, der Österreichischen Krebsgesellschaft-Krebsliga

unter Fortführung der «Österreichischen Zeitung für Onkologie»

Schriftleitung

W. Queißer, Mannheim

Fachschriftleitung

W. Berdel, Berlin

E. Dühmke, Göttingen

N. Jaeger, Bonn

M. Kaufmann, Heidelberg

P. Schlag, Heidelberg

Wissenschaftlicher Beirat

W. Berdel, Berlin V. Diehl, Köln C.H. Dittrich, Wien P. Drings, Heidelberg E. Dühmke, Göttingen S. Eckhardt, Budapest H. Ehrhart, München H.H. Fiebig, Freiburg A. Gläser, Halle R. Hartenstein, München K. Havemann, Marburg K.P. Hellriegel, Berlin R. Herrmann, Berlin H.

W. von Heyden, Einbeck D. Hoelzer, Frankfurt/M. J.H. Holzner, Wien

H. Huber, Innsbruck H.J. Illiger, Oldenburg N.Jaeger, Bonn W.F. Jungi, St. Gallen M.

Kaufmann, Heidelberg U.R. Kleeberg, Hamburg B. Kornhuber, Frankfurt/M. H. Löffler, Kiel H.

Ludwig, Wien U. Mohr, Hannover K. Munk, Heidelberg G.A. Nagel, Vitikon-Zürich A.

Pfleiderer, Freiburg F. Porzsolt, Ulm K. Possinger, München W. Queißer, Mannheim

P. Schlag, Heidelberg

H.-J. Schmoll, Hannover

M. Schroder, Kassel

S. Seeber, Essen

W. Vahlensieck, Bonn

M. Wannenmacher, Heidelberg

H. J. Weh, Hamburg

W. Wilmanns, München

W. Wrba, Wien

Die Zeitschrift erscheint zweimonatlich; pro Jahr erscheint 1 Band zu je 6 Heften. 
Bezugspreis für Jahrgang 14, 1991, DM 148 -/öS 1036,-/SFr 116,-. 1 Einzel-heft kostet DM 28,-1 öS 196.--/SFr 22,-, einschließlich MwSt.. zuzüglich Post-gebühren.

Der Abonnementpreis ist im voraus zahlbar. Das Abonnement der Zeitschrift läuft weiter, wenn es nicht spätestens 4 Wochen vor Abschluß eines Bandes abbestetlt wird.

Abonnementbestellungen können bei jeder Buchhandlung oder direkt beim Verlag aufgegeben werden:

Bundesrepublik DeutschlandlÖsterreich: S. Karger GmbH, Postfach 1724.

D-8034 Germering/München, Telefon (089) 843035, Telex 524865 D, Telefax

8418083, Postgiro München 40080-807

Schweiz: S. Karger AG. Allschwilerstr. 10, Postfach. CH-4009 Basel, Telefon

(061) 3061111, Telex 62652 CH, Telefax (061) 3061234

Anzeigen

S. Karger Verlag für Medizin und Naturwissenschaften GmbH, Postfach 1724, D-8034

Germering, Telefon (089) 843035. Gültig ist die Preisliste Nr. 6 vom 1.10.1990.

Für den Inhalt außerhalb des redaktionellen Teiles (insbesondere Anzeigen,

Industrieinformationen, Pressezitate und Kongreßinformationen) übernehmen Schriftleitung,

Beirat und Verlag keine Gewähr.

Eine Markenbezeichnung kann warenzeichenrechtlich geschützt sein, auch wenn bei îhrer

Verwendung in dieser Zeitschrift das Zeichen ${ }^{\circledR}$ oder ein anderer Hinweis auf etwa bestehende Schutzrechte fehlen sollte. Für Satzfehler, insbesondere bei Dosierungsangaben, wird keine

Gewähr übernommen.

Die Zeitschrift sowie alle in ihr enthaltenen einzelnen Beiträge und Abbildun-gen sind urheberrechtlich geschützt. Jede Verwertung, die nicht ausdrücklich vom Urheberrechtsgesetz zugelassen ist, bedarf der vorherigen Zustimmung des Verlags. Das gilt insbesondere für Vervielfältigungen. Bearbeitungen, Über-setzungen, Mikroverfilmungen und die Einspeicherung und Verarbeitung in elektronischen Systemen. Fotokopien dürfen nur für den persönlichen Gebrauch als Einzelkopien hergestellt werden. Jede im Bereich eines gewerblichen Unternehmens zulässig hergestellte oder benutzte Kopie dient gewerblichen Zwecken gem. § 54(2) UrhG und verpflichtet zur Gebührenzahlung an die Verwertungsgesellschaft WORT, Abt. VG

Wissenschaft, Goethestraße 49, D-8000 München 2.

(C) Copyright 1991 by S. Karger

Verlag für Medizin und Naturwissenschaften GmbH

Postfach 1724

D-8034 Germering (BRD)

Verlagsleitung: Manfred Just Redaktionsassistenz: Anne Schieber Anzeigenverkauf: Marlene Scholz Anzeigenverwaltung: Eva Lindenau Herstellung: Horst H. Bruch Vertrieb: Gabriela Taube

Satz und Druck: Walter Biering GmbH Grafischer Betrieb Freisinger Landstraße 21 D-8000 München 45 (BRD)

KAHGER 